\title{
Defective Neuronal Sprouting by Human Apolipoprotein E4 Is a Gain-of-Negative Function
}

\author{
B. Teter, ${ }^{1 \star}$ P-T. Xu, ${ }^{2}$ J.R. Gilbert, ${ }^{2}$ A.D. Roses,${ }^{3}$ D. Galasko, ${ }^{4}$ G.M. Cole ${ }^{1}$ \\ ${ }^{1}$ Veterans Administration Greater Los Angeles Healthcare System and Department of Medicine, University of \\ California, Los Angeles, Sepulveda, California \\ ${ }^{2}$ Duke University, Durham, North Carolina \\ ${ }^{3}$ Research and Development, Glaxo Wellcome \\ ${ }^{4}$ University of California San Diego, San Diego, California
}

The apolipoprotein $\mathrm{E}(\mathrm{apoE})$ epsilon 4 allele (apoE4) is a major risk factor for neurodegenerative conditions, including Alzheimer's disease (AD). A role for apoE in regeneration of synaptic circuitry after neural injury has been shown in several in vitro studies in which apoE3 supports neuronal sprouting better than apoE4. We evaluated sprouting in an in vitro mouse organotypic hippocampal slice culture system derived from transgenic mice expressing apoE3 or apoE4, in which apoEdependent granule cell mossy fiber sprouting in the presence of apoE4 is only $51 \%$ of the level of apoE3. Sprouting supported by apoE4 had a dose response opposite that by supported by apoE3: although increasing E3 expression increased sprouting, increasing E4 expression decreased sprouting, suggesting that the defect in E4 in supporting neuronal sprouting is a gain-of-negative activity. These results may have important pharmacogenomic implications for $A D$ therapies that modulate apoE expression levels. ๑ 2002 Wiley-Liss, Inc.

Key words: apolipoprotein E; neurite sprouting; transgenic mice; Alzheimer's disease

Apolipoprotein E (apoE) was first described as a component of several classes of plasma lipoproteins regulating lipid metabolism. In the central nervous system (CNS), apoE is expressed by astrocytes, microglia, and, to a lesser extent, neurons (in humans). There are three human isoforms of apoE protein, E2, E3, and E4, which differ at two positions (112 and 158); E3 and E4 differ at only 112, where E3 retains a cysteine (Weisgraber, 1990). The discovery in 1993 that the apoE allele epsilon $(\boldsymbol{\epsilon}) 4$ is a major risk factor for sporadic and late-onset familial Alzheimer's disease (AD) has brought attention to the role of apoE in neurodegenerative conditions. ApoE isotypespecific activities could impact neurodegeneration and neuroregeneration through several direct and indirect mechanisms, raising the possibility that apoE isotypes differ in the pathological mechanism by which they impact AD (Ritchie and Dupuy, 1999).
ApoE is an abundant lipoprotein, which appears to be involved in membrane remodeling, repair, and lipid redistribution, especially after neuronal injury. The major epidemiological effect of the $A P O E-\epsilon 4$ allele in $\mathrm{AD}$ is to accelerate the age of onset, by as much as 15 years, which may explain the three- to tenfold increased risk of $\mathrm{AD}$ with $A P O E-\epsilon 4$ when age-matched comparisons are made in risk determination (Ritchie and Dupuy, 1999). In the etiology of ongoing neurodegeneration, accelerated clinical onset could be caused by defective compensatory mechanisms. Stimulating compensatory synaptogenesis, or neurite sprouting, is a major CNS activity of apoE, one in which apoE4 is clearly defective in most in vitro studies. Neurite sprouting measured in neuron cell lines and primary neurons is stimulated by apoE3, whereas E4 shows inhibitory effects, no effect, or weakly stimulatory effects on sprouting, always less than (or equal to) those of E3; the variable activity of apoE4 has been attributed, in part, to the different lipidation states of pure vs. cell-derived apoE. Results presented here extend these studies on sprouting to use of the human $A P O E-\epsilon 3$ and $A P O E-\epsilon 4$ transgenics (with balanced expression in all cell types) in an organotypic hippocampal slice culture (OHSC) system, in which apoE is expressed and lipidated in a physiologically relevant manner. The activity of apoE isotypes in granule neuron mossy fiber sprouting was investigated using transgenic mice that express apoE at different levels depending

Contract grant sponsor: U.S. Veteran's Administration; Contract grant sponsor: Alzheimer's Association; Contract grant sponsor: Claude Pepper Older American's Independence Center (NIA); Contract grant sponsor: UCLA ADRC; Contract grant number: NIA AG16570.

*Correspondence to: B. Teter, Veterans Administration Greater Los Angeles Healthcare System and Department of Medicine, University of California, Los Angeles, 16111 Plummer St. MC151, Sepulveda, CA 91343. E-mail: bteter@ucla.edu

Received 25 October 2001; Revised 17 January 2002; Accepted 18 January 2002 
on the gene copy number. Because apoE expression is up-regulated in glial reactive responses to neurodegeneration, the dose responses of apoE activities could play an important role in its activity in AD. Results show that apoE3 and apoE4 are qualitatively different in their abilities to support neuronal sprouting when apoE expression levels increase.

\section{MATERIALS AND METHODS}

\section{Animals}

C56Bl/6J (Jackson Laboratories, Bar Harbor, ME) and C56Bl/6J-ApoE < tm1Unc $>$ [apoE-ko (Piedrahita et al., 1992) tenth-generation back-cross to C56Bl/6J by Jackson Laboratories] mice were maintained as inbred colonies. Human $A P O E-\epsilon 3$ and $A P O E-\epsilon 4$ (driven by the human APOE promoter) transgenic mice were made in the apoE-ko background and show equivalent levels of expression in CNS cells (Xu et al., 1996). Human apoE isoforms are expressed in astrocytes, microglia, and, to a lesser extent, neurons, as seen in humans [which is determined by the human $A P O E$ promoter elements (Roses et al., 1998)], and maintains, to an unknown extent, the human pattern of expression regulation and regional expression (Xu et al., 1996, 1998, 1999). Hemizygous (one gene copy) and homozygous (two gene copies) animals were generated by hemizygous crosses. Both littermates and nonlittermates were compared in all analyses; no significant effects between litters were detected in any analyses (data not shown). APOE- $\epsilon 3$ and $A P O E-\epsilon 4$ transgene copy number was determined by quantitative PCR amplification of tail-cut DNA samples; mouse apoE gene copy number was determined by using genotyping primers that detect both wild-type and knockout genes (data not shown). All surgical and animal care procedures were carried out in strict adherence to NIH Publication No. 80-23. Mice were kept on a $12 \mathrm{hr}$ light-dark cycle and provided food and water ad libitum.

\section{OHSC}

Postnatal day 7 pups were anesthetized with $\mathrm{CO}_{2}$ and hippocampal slice cultures prepared as described elsewhere (Stoppini et al., 1991), with some modifications (Harris-White et al., 1998). Hippocampi were sliced to $400 \mu \mathrm{m}$, placed on a membrane insert (Costar, Cambridge, MA) with $1.2 \mathrm{ml}$ media consisting of 64\% minimal essential medium + HEPES (Gibco, Grand Island, NY), 32\% Hank's balanced salt solution (Sigma, St. Louis, MO), $6.5 \mathrm{mg} / \mathrm{ml}$ glucose, penicillin-streptomycin (50 U/ml; $0.05 \mathrm{mg} / \mathrm{ml}$ ), and the serum substitute TCM (final concentration 2\%; ICN Biomedicals, Costa Mesa, CA). The medium was changed every 2 days for the 6 days in vitro (DIV), then every 3 days. Cultures were maintained for 18 DIV.

\section{Timm's Heavy Metal Staining}

The Timm's stain procedure was adapted for slice cultures as described elsewhere (Zimmer and Gahwiler, 1987). Briefly, at 18 DIV, cultures are treated with $1 \% \mathrm{Na}_{2} \mathrm{~S}$ for $10 \mathrm{~min}$ and developed with buffered $\mathrm{AgNO}_{3}$ for $35-40 \mathrm{~min}$ at $26^{\circ} \mathrm{C}$. The membrane was mounted on slides in Permount for image analysis.

\section{Quantitation of Mossy Fiber Sprouting}

Timm's stained mossy fiber sprouting was quantitated as previously described (Coltman et al., 1995), with minor modifications (Teter et al., 1999a). Briefly, digitized images of slices were video captured using NIH Image software, with treatment group blind to the operator, and the Timm's staining was quantitated in two supragranular regions, ventral and dorsal. Optical density was measured in a $100 \times 50 \mu \mathrm{m}$ box placed over the three most intensely staining areas within each of the dorsal, ventral, and central hilar regions. The two supragranular measures were corrected by subtracting background transmittance measurements taken in the adjacent hippocampal fissure, then dividing by the hilus measurement, which gives the sprouting index; this normalization to the hilus eliminates variability because of Timm's staining differences between cultures and between experiments (Coltman et al., 1995). The sprouting indices were analyzed by ANOVA with Fisher's PLD post hoc test to assess the significance of differences between groups and by testing the equality of slopes for differences between regression analyses (Sokal and Rohlf, 1981).

\section{Human ApoE ELISA}

Media from OHSC were collected at DIV 18, after 3 days of conditioning. Human apoE was measured by sandwich ELISA, using 2E1 monoclonal antibody to apoE (BoehringerMannheim, Indianapolis, IN) to capture and goat anti-human apoE antibody (Chemicon, Temecula, CA) to detect, with alkaline phosphatase as reporter, as described elsewhere (Gracia et al., 1994).

\section{RESULTS}

Mossy fiber sprouting in OHSC was previously shown to be dependent on mouse apoE expression (Teter et al., 1999a) and on human apoE isotype (Teter et al., 1999b). Because apoE4 is defective compared with apoE3, we evaluated the nature of the apoE4 defect by measuring mossy fiber sprouting in OHSC as a function of human apoE isotype expression level, when modulated by apoE gene copy number; hemizygous (one transgene copy) and homozygous (two transgene copies) animals were generated by hemizygous crosses. Mossy fiber sprouting was measured by image analysis of Timm's stained mossy fibers that sprout into the dorsal (suprapyramidal) outer molecular layer of the dentate gyrus, expressed as a sprouting index (see Materials and Methods).

For one-gene animals, apoE4 showed significantly less sprouting than apoE3 (Fig. 1); the sprouting index for apoE 4 was only $51 \%$ of that of apoE3 $(P<0.01)$, essentially as previously observed (Teter et al., 1999b). For both apoE3 and apoE4, one-gene animal sprouting indices were significantly different from those of two-gene animals. However, the direction of change was opposite: whereas two-gene apoE3 showed a $49 \%$ increase in the sprouting index $(0.51 \pm 0.11$ vs. $0.76 \pm 0.06 ; P<0.01)$, two-gene apoE4 showed a $54 \%$ decrease $(0.26 \pm 0.06$ vs. $0.12 \pm 0.05 ; P<0.01)$. To rule out the possibility that the lower initial sprouting levels of apoE4 precluded the ability to increase sprouting when the gene dose is doubled, apoE3 cultures were evaluated at a time point when the 


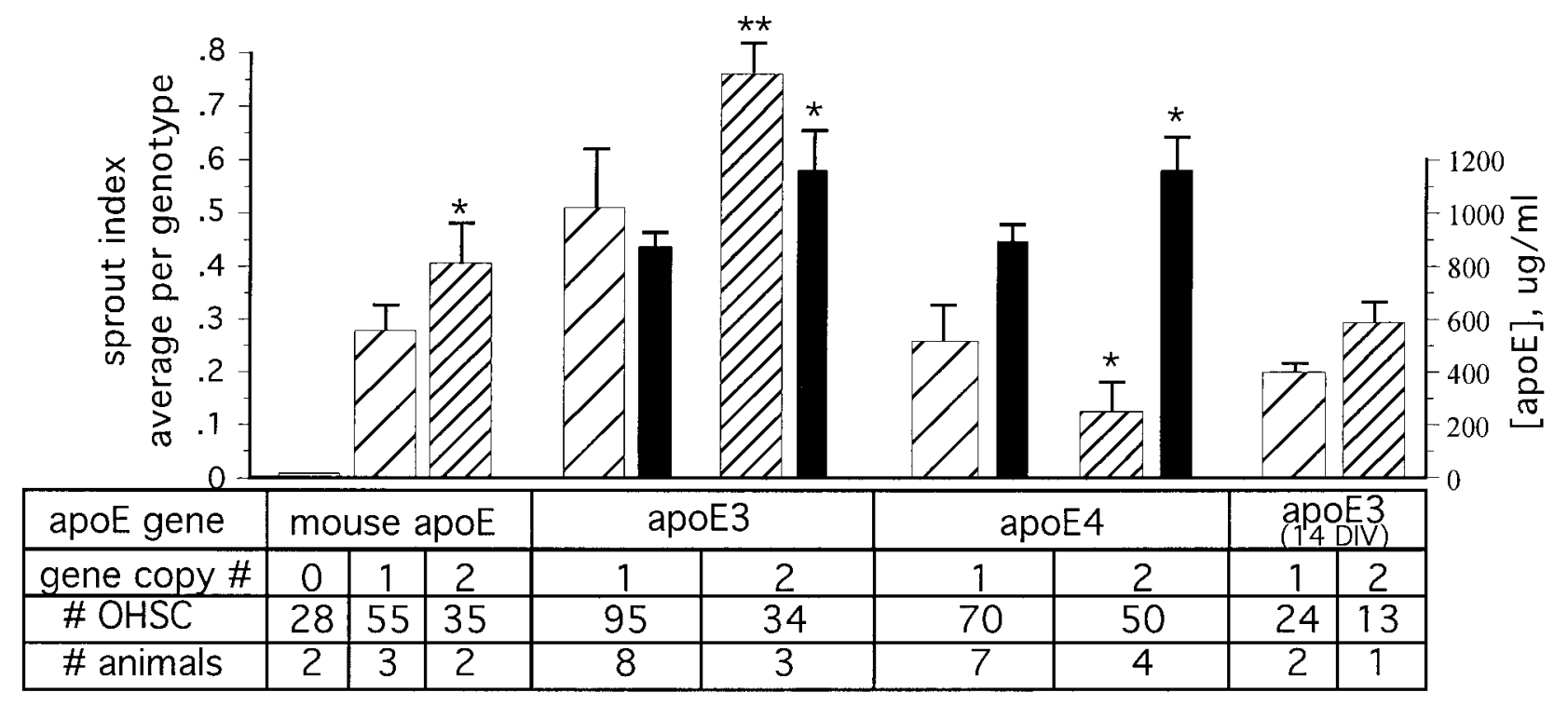

Fig. 1. Mossy fiber sprouting index and apoE protein levels in OHSC. The mean sprouting indices (hatched bars) for one-gene and two-gene mouse $A P O E$ and human $A P O E-\epsilon 3$ (apoE3) and $A P O E-\epsilon 4$ (apoE4) transgenic mice OHSC are shown as well as human apoE protein levels as determined by ELISA (black bars). Cultures were terminated at 18 DIV, except where indicated. Note that the sprouting index of apoE3 (one-gene) at $14 \mathrm{DIV}$ was equivalent to that of apoE4 (one-gene) at 18

sprouting index was similar to that of apoE4. ApoE3 cultures were prematurely terminated (at 14 DIV) to make the sprouting index of one-gene apoE3 equivalent to that of one-gene apoE4 cultures at 18 DIV. The increased sprouting in two-gene apoE3 cultures was still seen even at this lower one-gene sprouting level (Fig. 1).

Mouse apoE is similar, in part, to human apoE4 in the critical cysteine/arginine residues at 112 and 158, yet it has many other differences that could modify an apoE4like phenotype [notably, the absence of arginine at 61, which is critical for apoE4-specific activity (Weisgraber, 2001)]. To determine whether mouse apoE had activity like that of apoE4, the phenotype of mouse apoE was tested by similar copy number manipulation, using hemizygous crosses to generate mice with zero, one, or two mouse apoE gene copies. As shown in Figure 1, the complete lack of sprouting in zero-gene OHSC (essentially apoE-knockout) reflects the apoE dependence of this sprouting paradigm, as previously described (Teter et al., 1999a). Mouse apoE showed a $52 \%$ increase in the sprouting index between one- and two-gene OHSC (0.27 \pm 0.05 vs. $0.41 \pm 0.08 ; P<0.05$; Fig. 1). These results indicate that mouse apoE behaves qualitatively similarly to human apoE3 in this sprouting activity.

To modulate apoE expression levels and measure the effect on sprouting, human apoE transgene copy number was varied. The OHSC derived from one-gene and twogene animals showed proportional levels of apoE protein in the culture media (as measured by ELISA), as shown in Figure 1; variable levels of apoE in different wells (Fig. 2)
DIV and that the apoE3 two-gene cultures showed a trend of increased sprouting even at this earlier point. Differences between one-gene and two-gene groups were statistically significant, as indicated $\left({ }^{\star} P<0.05\right.$, $\star \star P<0.01)$; standard deviations are shown. The number of OHSC slices and animals from which they were derived are indicated; for culture, two wells were used for each animal containing OHSC from one hippocampus each.

were largely caused by different numbers of surviving slices in each well (this varied from five to nine slices per well and was proportional to the apoE level in each well; data not shown). The average sprouting index of the five to nine slices in each well was plotted against the level of apoE protein in the well medium (Fig. 2). For apoE3, sprouting was positively correlated with increased apoE levels, whereas, for apoE4, sprouting was negatively correlated with increased apoE levels; linear regression analysis showed slopes of $+7 \times 10^{-4}$ for apoE3 3 and $-5 \times 10^{-4}$ for apoE4 and $\mathrm{R}^{2}$ values of 0.61 for apoE3 and 0.59 for apoE4. Irrespective of gene copy number, variations in apoE protein levels were strong determinants of the sprouting index. These results show that these two apoE isotypes are qualitatively different in their dose-dependent support of mossy fiber sprouting. ApoE3 showed increased sprouting with increasing expression, indicative of a positive activity for sprouting, whereas apoE4 showed decreased sprouting with increasing expression, indicative of a gain-of-negative activity.

\section{DISCUSSION}

ApoE4 influences the risk of AD through its pleiotropic effects on both the pathology of $\mathrm{AD}$ and the environmental and developmental factors influencing its etiologies (Teter, 2000; Teter et al., 2002). Clearly, apoE4 influences neurodegeneration in AD (Poirier, 1994) and age-dependent neurodegeneration in apoE4 transgenic mice (Buttini et al., 1999). This may be related to its effects on $\mathrm{Ca}^{2+}$-dependent neurotoxicity (Marques et al., 1996; 


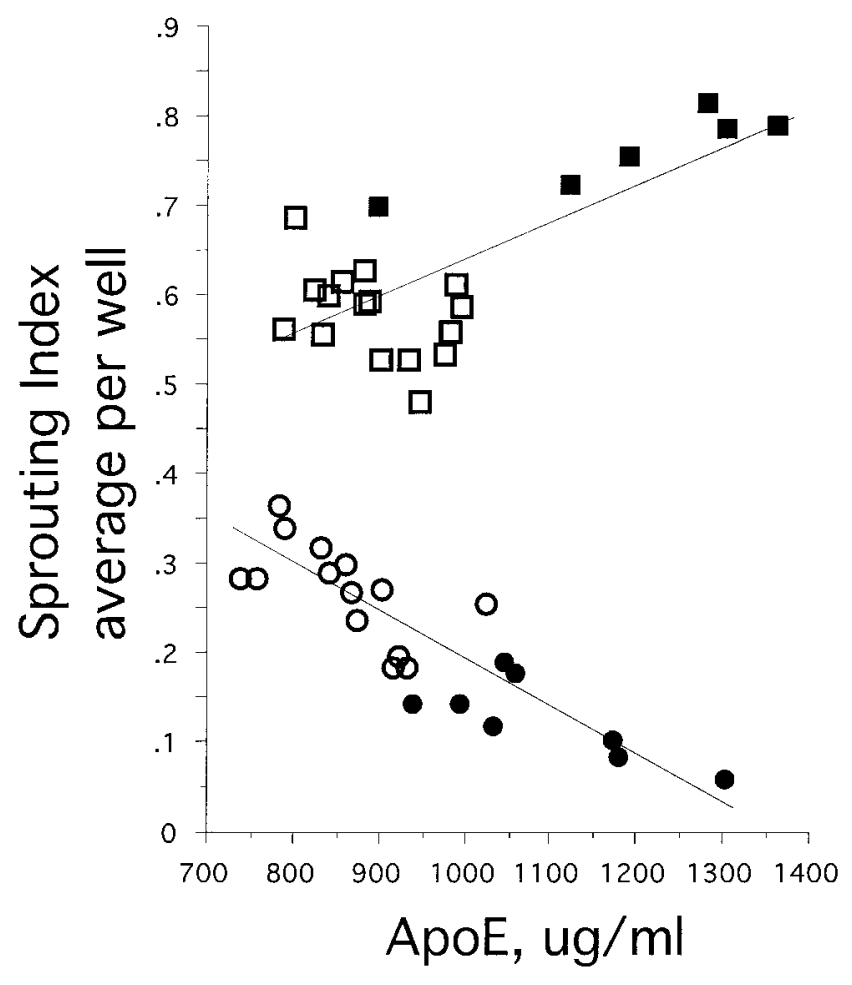

Fig. 2. The relationship between the sprouting index and the apoE protein level is isotype dependent. The OHSC derived from one-gene and two-gene animals (open and solid symbols, respectively) expressed variable levels of apoE protein in the well culture media (see Results), and this is plotted against the average index of mossy fiber sprouting for all slices in the well (for clarity, error bars of individual well sprouting indices are omitted; the average sprouting index standard deviation was \pm 0.08 ). Linear regression analysis showed that apoE3 (squares) had a slope of $+7 \times 10^{-4}$, whereas apoE4 (circles) had a slope of $-5 \times 10^{-4}$. The $\mathrm{R}^{2}$ values were 0.61 for E3 and 0.59 for E4. A test utilizing all individual slice sprouting indices (not the mean values shown here) indicated that the slopes of the regression analyses are different $(P<$ $0.0001)$

Muller et al., 1998), cholesterol metabolism (Michikawa and Yanagisawa, 1998), or oxidative damage (Miyata and Smith, 1996; Ramassamy et al., 1999; Pedersen et al., 2000; Jolivalt et al., 2000). The regenerative capacity of the CNS can, in principle, counteract some neurodegeneration, yet behavioral deficits are persistent in apoE4 transgenics (Raber et al., 1998, 2000; Buttini et al., 1999). Regeneration of synaptic circuitry in response to neurodegeneration could be one mechanism that delays the onset of $\mathrm{AD}$, explaining an important epidemiologic defect in apoE4 populations (for reviews see Mesulam, 1999; Arendt, 2001; Teter, 2000b).

The mechanism by which apoE facilitates neuronal sprouting may involve lipid trafficking. Recently, apoE and the cholesterol it carries were identified as the glial factor that stimulates new synapse formation in cultured neurons (Mauch et al., 2001). The activity of apoE in supporting neuronal regeneration has received much sup- port, with apoE4 consistently showing defects. In most studies, apoE4 was defective in supporting neurite sprouting (Table I). Possible mechanisms include isotype-specific effects on lipid efflux (Michikawa et al., 2000), apoE cellular accumulation (Nathan et al., 1995; Ji et al., 1998), microtubule metabolism (Nathan et al., 1995), or neurotoxicity (Marques et al., 1996) (for reviews see Teter, 2000, 2002; Teter et al., 2002). Critical issues yet to be fully resolved are the effects of the lipidation state of apoE and neuronal expression of human apoE. Results presented here use human $A P O E-\epsilon 3$ and $A P O E-\epsilon 4$ transgenics that express apoE in vivo with cellular specificity like that seen in humans (Xu et al., 1996, 1998, 1999) and, therefore, in a physiologically relevant lipidation state. In the OHSC system, not only is apoE4 partially defective in supporting mossy fiber sprouting compared with apoE3 but increased levels of apoE4 further exacerbated the defect, indicating that the defect in apoE4 is a gain-ofnegative activity. Studies using dorsal root ganglion and primary cortical neurons have shown a similar dosedependent effect with similar concentrations of pure E3 and E4 (Nathan et al., 1994, 2002), although E4 did not stimulate the basal (apoE-independent) sprouting; in contrast, in the OHSC system, basal sprouting (that of apoEknockout mice) is essentially zero (Fig. 1), and apoE4 showed weak sprouting activity. The apparent gain-ofnegative activity of apoE4 could be a form of toxicity that, at higher doses, dominates its weak sprouting activity. This could be relevant at the apoE levels measured in OHSC media, because similar levels are found in human cerebrospinal fluid and brain (2-6 $\mu \mathrm{g} / \mathrm{ml}$; Hesse et al., 2000).

Because apoE expression is increased in most neurodegenerative conditions as part of glial activation responses, the dose responsiveness of isotype-specific activities bears not only on our understanding of isotypespecific effects but also on the therapeutic implications of altering apoE expression levels. However, this has received little experimental attention. In addition to the present work, another recent application of the transgenic approach has revealed a similar gene-dose response to neurodegeneration, in which two-copy apoE4 animals had greater loss of synaptic markers (synaptophysin, MAP2, and neurofilament) at 8 months (Buttini et al., 2000). In addition, apoE4 was dominant over apoE3 in these measures, similar to results for sprouting in vitro (Holtzman et al., 1995; Nathan et al., 1995). These results may provide insight into the mechanism of apoE4 in $\mathrm{AD}$, in which apoE4 reduced dendritic remodeling of pyramidal and subcortical neurons; $A P O E-\epsilon 4$ copy number affected the relationship and possible "coupling" between neuronal degeneration and dendritic growth, with $€ 4 / \epsilon 4$ showing no relationship and a shift toward proximal branching (for review see Arendt, 2001). The latter effect of apoE4 on branching is seen in vitro (Nathan et al., 1995) and may explain the reduced distal mossy fiber sprouting measured here in OHSC (outer molecular layer sprouting).

The gain-of-negative function of E4 could have important clinical implications for the pharmacogenomic 
TABLE I. ApoE4 Is Defective in Supporting Neurite Sprouting In Vitro

\begin{tabular}{|c|c|c|c|c|}
\hline ApoE source & Neurite source & $\begin{array}{c}\text { ApoE4 effect } \\
\text { (apoE3 stimulates) }\end{array}$ & Depends on & References \\
\hline Pure & $\begin{array}{l}\text { DRG and } \\
1^{\circ} \text { cortical neuron }\end{array}$ & Inhibits & Lipoprotein, apoE levels & $\begin{array}{l}\text { Handelmann et al., 1992; } \\
\text { Nathan et al., 1994; } \\
\text { Nathan et al., } 2002\end{array}$ \\
\hline Pure & $\mathrm{N} 2 \mathrm{~A}$ & Inhibits & $\beta-V L D L, L D L R / L R P$ & $\begin{array}{l}\text { Nathan et al., 1994; } \\
\text { Nathan et al., } 1995\end{array}$ \\
\hline Transfected N2A low expressing & $\mathrm{N} 2 \mathrm{~A}$ & Inhibits & $\beta-V L D L, H S P G / L R P$ & Bellosta et al., 1995 \\
\hline Transfected N2A high expressing & $\mathrm{N} 2 \mathrm{~A}$ & Neutral & & DeMattos et al., 1998 \\
\hline Pure & GT1-1 (a HT line) & Neutral & $\beta-V L D L$, LRP & Holtzman et al., 1995 \\
\hline Human plasma HDL, CSF lipoproteins & GT1-1 (a HT line) & Neutral & LRP & Fagan et al., 1996 \\
\hline GFAP transgenic astrocyte & $1^{\circ} \mathrm{HC}$ neuron & Neutral & LRP & Sun et al., 1998 \\
\hline Pure (no lipid) + laminin & $1^{\circ} \mathrm{HC}$ neuron & Stimulates $(=\mathrm{E} 3)$ & & Huang et al., 1995 \\
\hline Transfected HEK cells & $1^{\circ} \mathrm{HC}$ neuron & Stimulates $(=\mathrm{E} 3)$ & & Puttfarcken et al., 1997 \\
\hline Human $A P O E$ transgenic OHSC & Granule neurons & $\begin{array}{l}\text { a) Stimulates ( }=58 \% \text { of E3) } \\
\text { b) "Inhibits" by dose }\end{array}$ & b) ApoE levels & $\begin{array}{l}\text { a) Teter et al., 1999b } \\
\text { b) This study }\end{array}$ \\
\hline
\end{tabular}

efficacy of therapeutic drugs that impact or target apoE expression (Poirier, 1999; Saunders et al., 2000). For example, the efficacy of estrogen replacement therapy (ERT) in improving the cognitive deficits in postmenopausal women with AD (van Duijn et al., 1996) may reflect stimulation of neurite sprouting (Stone et al., 1998; Teter et al., 1999a) through stimulation of apoE expression (Stone et al., 1997). Indeed, APOE- $\epsilon 4$ women show no benefit of ERT (Yaffe et al., 2000) and showed less response to tacrine (anticholinesterase) therapy (Schneider and Farlow, 1997). It will be important to evaluate apoE genotype effects in trials of other drugs that can modulate apoE expression.

\section{ACKNOWLEDGMENT}

The authors were assisted with the statistical analysis by Dr. Judith Harker (VA-GLAHS).

\section{REFERENCES}

Arendt T. 2001. Alzheimer's disease as a disorder of mechanisms underlying structural brain self-organization. Neuroscience 102:723-765.

Bellosta S, Nathan BP, Orth M, Dong LM, Mahley RW, Pitas RE. 1995. Stable expression and secretion of apolipoproteins E3 and E4 in mouse neuroblastoma cells produces differential effects on neurite outgrowth. J Biol Chem 270:27063-27071.

Buttini M, Orth M, Bellosta S, Akeefe H, Pitas RE, Wyss-Coray T, Mucke L, Mahley RW. 1999. Expression of human apolipoprotein E3 or E4 in the brains of apoe-/- mice: isoform-specific effects on neurodegeneration. J Neurosci 19:4867-4880.

Buttini M, Akeefe H, Lin C, Mahley RW, Pitas RE, Wyss-Coray T, Mucke L. 2000. Dominant negative effects of apolipoprotein E4 revealed in transgenic models of neurodegenerative disease. Neuroscience 97:207210.

Coltman BW, Earley EM, Shahar A, Dudek FE, Ide CF. 1995. Factors influencing mossy fibers collateral sprouting in organotypic slice cultures of neonatal mouse hippocampus. J Comp Neurol 362:209-222.

DeMattos RD, Curtiss LK, Williams DL. 1998. A minimally lipidated form of cell-derived apolipoprotein E exhibits isoform-specific stimulation of neurite outgrowth in the absence of exogenous lipids or lipoproteins. J Biol Chem 273:4206-4212.

Fagan AM, Bu G, Sun Y, Daugherty A, Holtzman DM. 1996. Apolipoprotein E-containing high density lipoprotein promotes neurite outgrowth and is a ligand for the low density lipoprotein receptor-related protein. J Biol Chem 271:30121-30125.

Gracia V, Fiol C, Hurtado I, Pintó X, Argimon JM, Castiñeiras MJ. 1994. An enzyme-linked immunosorbent assay method to measure human apolipoprotein E levels using commercially available reagents: effect of apolipoprotein E polymorphism on serum apolipoprotein E concentration. Anal Biochem 223:212-217.

Handelmann GE, Boyles JK, Weisgraber KH, Mahley RW, Pitas RE. 1992. Effects of apolipoprotein E, B-very low density lipoproteins, and cholesterol on the extension of neurites by rabbit dorsal root ganglion neurons in vitro. J Lipid Res 33:1677-1688.

Harris-White ME, Frautschy SA, Cole GM. 1998. Methods for evaluating a slice culture model of Alzheimer's disease. In: Timiras P, Sternberg H, editors. Methods in brain aging. Berlin: Springer-Verlag. p 55-65.

Hesse C, Larsson H, Fredman P, Minthon L, Andreasen N, Davidsson P, Blennow K. 2000. Measurement of apolipoprotein E (apoE) in cerebrospinal fluid. Neurochem Res 25:511-517.

Holtzman DM, Pitas RE, Kilbridge J, Nathan B, Mahley RW, Bu G, Schwartz AL. 1995. Low density lipoprotein receptor-related protein mediates apolipoprotein E-dependent neurite outgrowth in a central nervous system-derived neuronal cell line. Proc Natl Acad Sci USA 92:9480-9484.

Huang DY, Weisgraber KH, Strittmatter WJ, Matthew WD. 1995. Interaction of apolipoprotein $\mathrm{E}$ with laminin increases neuronal adhesion and alters neurite morphology. Exp Neurol 136:251-257.

Ji ZS, Pitas RE, Mahley RW. 1998. Differential cellular accumulation retention of apolipoprotein $\mathrm{E}$ mediated by cell surface heparin sulfate proteoglycans-Apolipoproteins E3 and E2 greater than E4. J Biol Chem 273:13452-13460.

Jolivalt C, Lenninger-Muller B, Bertrand P, Herber R, Christen Y, Siest G. 2000. Differential oxidation of apolipoprotein $\mathrm{E}$ isoforms and interaction with phospholipids. Free Rad Biol Med 28:129-140.

Marques MA, Harmony JA, Crutcher KA. 1996. A thrombin cleavage fragment of apolipoprotein $\mathrm{E}$ and related synthetic peptides is receptormediated. Neuroreport 7:2529-2532.

Mauch DH, Nagler K, Schumacher S, Gorits C, Muller E-C, Otto A, Pfrieger FW. 2001. CNS synaptogenesis promoted by glial-derived cholesterol. Science 294:1354-1357.

Mesulam MM. 1999. Neuroplasticity failure in Alzheimer's disease: bridging the gap between plaques and tangles. Neuron 24:521-529.

Michikawa M, Yanagisawa K. 1998. Apolipoprotein E4 isoform-specific actions on neuronal cells in culture. Mech Ageing Dev 107:233-243. 
Michikawa M, Fan Q-W, Isobe I, Yanagisawa K. 2000. Apolipoprotein E exhibits isoform-specific promotion of lipid efflux from astrocytes and neurons in culture. J Neurochem 74:1008-1016.

Miyata M, Smith JD. 1996. Apolipoprotein E allele-specific antioxidant activity and effects on cytotoxicity by oxidative insults and B-amyloid peptides. Nat Genet 14:55-61.

Muller W, Meske V, Berlin K, Scharnagl H, Marz W, Ohm TG. 1998. Apolipoprotein E isoforms increase intracellular $\mathrm{Ca}^{2+}$ differentially through a omega-agatoxin IVa-sensitive $\mathrm{Ca}^{2+}$ channel. Brain Pathol 8:641-653.

Nathan BP, Bellosta S, Sanan DA, Weisgraber KH, Mahley RW, Pitas RE. 1994. Differential effects of apolipoproteins E3 and E4 on neuronal growth in vitro. Science 264:850-852.

Nathan BP, Chang K, Bellosta S, Brisch E, Ge N, Mahley RW, Pitas RE. 1995. The inhibitory effect of apolipoprotein E4 on neurite outgrowth is associated with microtubule depolymerization. J Biol Chem 270:1979119799.

Nathan BP, Jiang Y, Wong GK, Shen F, Brewer G, Struble RG. 2002. Apolipoprotein E4 inhibits, and apolipoprotein E3 promotes neurite sprouting in cultured adult mouse cortical neurons through a low-density lipoprotein receptor-related protein. Brain Res 928:96-105.

Pedersen WA, Chan SL, Mattson MP. 2000. A mechanism for the neuroprotective effect of apolipoprotein E: isoform-specific modification by the lipid peroxidation product 4-Hydroxynonenal. J Neurochem 74:14261433.

Piedrahita JA, Zhang SH, Hagaman JR, Oliver PM, Maeda N. 1992. Generation of mice carrying a mutant apolipoprotein $\mathrm{E}$ gene inactivated by gene targeting in embryonic stem cells. Proc Natl Acad Sci USA 89:4471-4475.

Poirier J. 1994. Apolipoprotein E in animal models of CNS injury and in Alzheimer's disease. Trends Neurosci 17:525-530.

Poirier J. 1999. Apolipoprotein E: a pharmacogenetic target for the treatment of Alzheimer's disease. Mol Diagn 4:335-341.

Puttfarcken PS, Manelli AM, Falduto MT, Getz GS, LaDu M-J. 1997. Effect of apolipoprotein $\mathrm{E}$ on neurite outgrowth and $\beta$-amyloid-induced toxicity in developing rat primary hippocampal cultures. J Neurochem 68:760-769.

Raber J, Wong D, Buttini M, Orth M, Bellosta S, Pitas RE, Mahley RW, Mucke L. 1998. Isoform-specific effects of human apolipoprotein E on brain function revealed in apoE knockout mice: increased susceptibility of females. Proc Natl Acad Sci USA 95:10914-10919.

Raber J, Wong D, Yu G-Q, Buttini M, Mahley RW, Pitas RE, Mucke L. 2000. Apolipoprotein E and cognitive performance. Nature 404:352253.

Ramassamy C, Averill D, Beffert U, Bastianetto S, Theroux L, LussierCacan S, Cohn JS, Christen Y, Davignon J, Quirion R. 1999. Oxidative damage and protection by antioxidants in the frontal cortex of Alzheimer's disease is related to apolipoprotein E genotype. Free Rad Biol Med 27:544-553.

Ritchie K, Dupuy AM. 1999. The current status of APO E4 as a risk factor for Alzheimer's disease: an epidemiological perspective. Int J Geriatr Psychiatr 14:695-700.

Roses AD, Gilbert J, Xu PT, Sullivan P, Popko B, Burkhart DS, ChristianRothrock T, Saunders AM, Maeda N, Schmechel DE. 1998. Cis-acting human apoE tissue expression element is associated with human pattern of intraneuronal apoE in transgenic mice. Neurobiol Aging 19:S53-S58.

Saunders AM, Trowers MK, Shimkets RA, Blakemore S, Crowther DJ, Mansfield TA, Wallace DM, Strittmatter WJ, Roses AD. 2000. The role of apolipoprotein $\mathrm{E}$ in Alzheimer's disease: pharmacogenomic target selection. Biochim Biophys Acta 1502:85-94.

Schneider LS, Farlow M. 1997. Combined tacrine and estrogen replacement therapy in patients with Alzheimer's disease. Ann NY Acad Sci 826:317-322.

Sokal RR, Rohlf FJ. 1981. Biometry, 2nd ed. San Franscico: W.H. Freeman.

Stone DJ, Rozovsky I, Morgan TE, Anderson CP, Hajian H, Finch CE. 1997. Astrocytes and microglia respond to estrogen with increased apoE mRNA in vivo and in vitro. Exp Neurol 143:313-318.

Stone DJ, Rozovsky I, Morgan TE, Anderson CP, Finch CE. 1998. Increased synaptic sprouting in response to estrogen via an apolipoprotein E-dependent mechanism: implications for Alzheimer's disease. J Neurosci 18:3180-3185.

Stoppini L, Buchs PA, Muller D. 1991. A simple method for organotypic cultures of nervous tissue. J Neurosci Methods 37:173-182.

Sun Y, Wu S, Bu G, Onifade MK, Patel SN, LaDu MJ, Fagan AM, Holtzman DM. 1998. Glial fibrillary acidic protein-apolipoprotein E transgenic mice: astrocyte-specific expression and differing biological effects of astrocyte-secreted apoE3 and apoE4 lipoproteins. J Neurosci 8:3261-3272.

Teter B. 2000. Apolipoprotein E isotype-specific effects in neurodegeneration. Alz Rep 3:199-212.

Teter B. 2002. Neuro-regenerative mechanisms in Alzheimer's disease. J Neurosci Res (submitted).

Teter B, Harris-White M, Frautschy SA, Cole GM. 1999a. Role of apolipoprotein $\mathrm{E}$ and estrogen in mossy fiber sprouting in hippocampal slice cultures. Neuroscience 91:1009-1016.

Teter B, Xu P-T, Gilbert JR, Roses AD, Galasko D, Cole GM. 1999b. Human apolipoprotein $\mathrm{E}$ isoform-specific differences in neuronal sprouting in organotypic hippocampal culture. J Neurochem 73:2613-2616.

Teter B, Raber J, Nathan B, Crutcher KA. 2002. The presence of apoE4, not the absence of apoE3, contributes to AD pathology. J Alz Dis (in press).

van Duijn CM, Meijer H, Witteman JC, Havekes LM, De Knijff P, Van Broeckhoven C, Hofman A. 1996. Estrogen, apolipoprotein E and the risk of Alzheimer's disease. Neurobiol Aging 16:S79-S80.

Weisgraber KH. 1990. Apolipoprotein E distribution among human plasma lipoproteins: role of the cysteine-arginine interchange at residue $112 . \mathrm{J}$ Lipid Res 31:1503-1511.

Weisgraber KH. 2001. Apolipoprotein E: structure-function relationships. Adv Prot Chem 45:249-302.

Xu P-T, Schmechel D, Rothrock T, Qiu H-L, Popko B, Sullivan P, Maeda N, Saunders A, Roses AD, Gilbert JR. 1996. Human apolipoprotein E2, E3, and E4 isoform specific transgenic mice: human-like pattern of glial and neuronal immunoreactivity in central nervous system not observed in wild type mice. Neurobiol Dis 3:229-245.

Xu P-T, Gilbert JR, Qiu H-L, Ervin J, Rothrock-Christian TR, Hulette C, Schmechel DE. 1999. Specific regional transcription of apolipoprotein E in human brain neurons. Am J Pathol 154:601-611.

Xu P-T, Gilbert JR, Qiu HL, Rothrock-Christian T, Settles DL, Roses AD, Schmechel DE. 1998. Regionally specific neuronal expression of human APOE gene in transgenic mice. Neurosci Lett 246:65-68.

Yaffe K, Haan M, Byers A, Tangen C. 2000. Estrogen use, APOE, and cognitive decline-Evidence of gene-environment interaction. Neurology 54:1949-1953.

Zimmer J, Gahwiler BH. 1987. Growth of hippocampal mossy fibers: a lesion and coculture study of organotypic slice cultures. J Comp Neurol 264:1-13. 